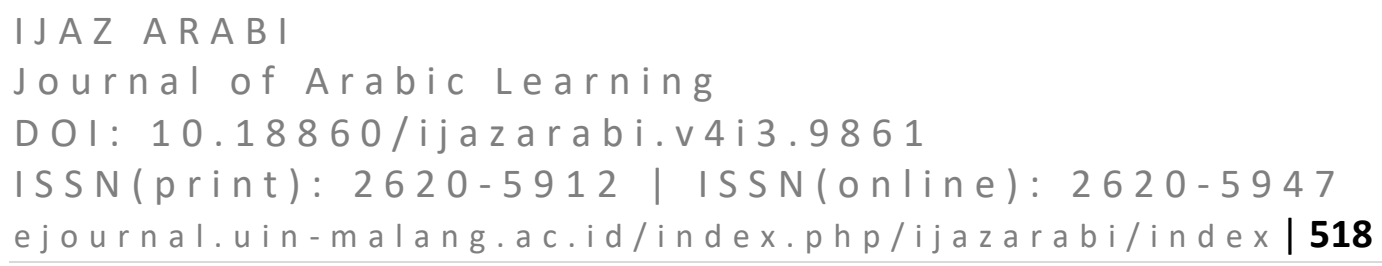

\title{
Mitigating Devices in Mosuli Iraqi Arabic With Reference To English
}

\author{
Ali Hussein Hazem ${ }^{1,2}$ Suha Idrees Mohammed ${ }^{3}$ \\ University of Al-Hamdaniya, Iraq ${ }^{1}$, University of Patras, Greece ${ }^{2}$, Nineveh \\ Directorate of Education, Ministry of Education, Iraq $^{3}$ \\ alihussein@uohamdaniya.edu.iq, suhaninawa@gmail.com
}

\begin{abstract}
The Mosuli dialect is the dialect of the people of the city of Mosul in northern Iraq. It is one of the dialects of northern Mesopotamia, which is an extension of the Arabic dialects that prevailed in Iraq and the Euphrates Island in the Abbasid era. The Mosuli dialect, like other dialects of northern Mesopotamia, contains some of the ancient characteristics that are found in Standard Arabic, but it also has some unique features which distinguish it from the others. In comparison with the dialects of southern Mesopotamia, this dialect retains the features of urban dialects such as the letter qaaf. This study explores the most common uses, and the different types of expressions of mitigation used by people who speak the Mosuli Iraqi Arabic dialect in their everyday life in different situations. Mitigating devices are speech utterances used to lesson the force of the speech on the listener to avoid facethreatening situations. Although mitigating devices are widely used in writing and speaking, they have not been adequately investigated in previous studies. It is assumed that people use mitigation to lesson the force of direct speech. In order to prove this surmise, the data are collected from the native speakers of Mosuli Arabic dialect and analyzed according to Fraser's 1981 model. The findings reveal that many participants use several expressions with the appropriate mitigating devices suited to different situations. More importantly, the findings show new ways of communication for those interested in the study of pragmatics in the Arabic language as well as English and in the language of other non-native speakers of Arabic.
\end{abstract}

Keywords: Mitigating Devices; Politeness; Indirect Speech; Hedging; Euphemism; Arabic-English

\section{INTRODUCTION}

Language mitigation denotes to approaches that people espouse to avoid face-threatening circumstances in dialog and thus to linguistically overhaul the harm done to someone's face by what the speaker says or does. Various articles exploring mitigation have been .

from various authors viewpoints. Thus, some authors attempted to equate mitigation with politeness, while other studies focused on mitigation as a separate topic. Despite the abundance of references to politeness techniques, euphemisms, hedges, and other devices in mitigation literature, there appears to be no clear attempt to determine what constitutes mitigation. Caffi (2007:48) surmises that "the 
concept of mitigation has so far mainly been used with reference to the set of strategies speakers service to lessen the effect of what 'Brown and Levinson (1987)' call 'face-threatening acts' (FTAs) (Ali and Salih. 2020:1)". The focus of this study is on mitigating devices applied in the speech of Mosuli Iraqi Arabic. This study is the first attempt at investigating the production of mitigation devices by Mosuli Iraqi Arabic people. Moreover, the effect of the informant's gender and their language proficiency on applying and perceiving mitigation devices will be studied. Mitigation is a branch of pragmatics whereby the force of the speech on the listener is lessoned by indirect speech which uses some expressions commonly found in everyday communication in the culture of a community. While the previous studies focused on the mitigating devices found in English and other languages such as politeness in Arabic, there aren't many studies dealing with these devices in the Mosuli Arabic Dialect. So, this study will fill the gap and we as researchers hope to contribute to the existing literature in the field of linguistics.

This study aims to show the mitigating devices that are used by native speakers of Mosuli Iraqi Arabic (MIA) and how these devices are used in their culture in various situations. The paper will be using the English translation as a framework of reference for this contrastive analysis. MIA is the dialect of the people living in the north of Iraq. The Mosuli dialect is considered nearest to Modern Standard Arabic( MSA) although it contains some old features which are not found in other dialects such as the letter " $ق$ " in Arabic or its equivalent 'q' in English.

The context of the speech, the speaker and the listener are very important factors in everyday communication. Moreover, some people have distinct notions about what should be said in certain situations, while it may be a matter of small significance for others. Hence, the usage of mitigating devices is constrained via the context. Therefore, in view of the contribution of previous studies this paper tries to answer are mitigating devices present in Mosuli Iraqi Arabic? What are the most popular mitigating devices that are used in Mosuli Iraqi Arabic? Is the context clear for the speaker and the listener? Will using the mitigation devices lesson the force of direct speech?

As we need mitigation devices in every interaction, the present study tries to show how the people use these devices in their social interaction. This study assumes that native speakers of MIA use mitigating devices to lesson the force of direct speech because of social factors, for instance: age, gender, and other factors. The speech of different people who are native to Mosul and speak the Mosuli dialect were collected and analyzed according to Fraser's 1981 model with close reference to the context of each utterance. The emphasis was on the impact of using these devices in everyday communication. Hence, the study attempts to show the influence of the context. It is limited to native speakers of Arabic viz Iraqi Mosuli people who live in Mosul.

The present work advances our knowledge of the features of the Mosuli dialect. The findings of the study may be of significance in the field of contrastive 
studies and universal language. As we have referred to speech acts, both specialists and students of linguistics stand to gain from this study. Finally, the present work has implications for authors who wish to present the features of the Mosuli dialect in different situations.

Mitigation is often viewed as part of the wider issue of politeness (Ali and Salih, 2020:32). Several linguists (Al-Ali and Alawneh, 2010; Al-Ali and Sahawneh, 2008; Abdul Sattar et al. 2009) among others observed the use of request variations in the Arabic culture. Their studies were mostly focused on Arab learners of English when they communicate English. For example, to lesson the inadvertent threat in a request for an invitation, the social aspects of the context should be kept in mind. Hence, the degree of mitigation correlates with three factors: (1) social remoteness, (2) relative power, usually resulting from social and economic status; and (3) force of obligation (Brown and Levinson,1987). Accordingly, Brown and Levinson (1987:42) address mitigation as "a synonym of politeness". When an invitation is initiated with an invitee on an equal ranking and familiarity, there will be a mitigation of mutual fears.

Abdul Sattar et al. (2009) conclude that Iraqi (informants of the study) may he /she are not aware of the social culture of English when they want to express for example a request.

Mitigating devices have been explored using different expressions . One of the most important concepts of pragmatics is politeness. Brown (1983) states that politeness is "a performance that conveys a confident anxiety for others". Other researchers like Holmes (1995:5) point out that polite acts include avoiding to call a friend early on a holiday. Accoerding to Holemes women like to utter positive politeness frequently regarding gender relationship. Other acts like (apologizing) for interrupting a speaker are termed as a negative politeness. In contrast, there are expressions or devices that are termed as positive politeness. Examples of this type are manifested in behaviours such as giving a birthday card to a friend or naming a child 'sweetie', etc. Similarly, Watts et al. (1992: 1-4) state that the notion of politeness has to do with the means human beings use to achieve effective interactive relationships to attain both individual and assembly language goals "Different structures and forms of a language and its practice allow the adherents of a socio-cultural assembly to achieve these goals" (ibid). Khuder et al. conclude their study by stating that discourse markers "are essential linguistic devices which guide the reader to the intended meaning" (Khuder et al. 2021: 22). Although the study gives no comparison in the features of mitigation in Arabic and English, it however looks at the extent; the mechanism is applicable in the two languages.

Mitigation, which our study is based on includes the following devices proposed by Fraser (1990): Indirect Speech Acts, Impersonal Constructions, Disclaimers, Parenthetical Verbs, Tag questions, Hedges and Euphemism. These devices are used by interlocutors to keep themselves versus different interactive perils. It is already made clear in the introduction that the study is not a comparative analysis in the true sense.The purpose to analyse the English examples is just to show the 
Journal of Arabic Learning

DOI: $10.18860 / \mathrm{ijazarabi.v4i3.9861}$

ISSN(print): 2620-5912 | ISSN(online): 2620-5947

ejournal.uin-malang.ac.id/index.php/ijazarabi/index

validity of the framework for languages from different families ( $c f$. Hazem and Meteab, 2019).

\section{METHOD}

In this part of the paper, the mechanisms for the analysis. Thus, the analysis is focused mainly on Arabic, especially MIA comparing them with English. The categorization used for the classification mitigating devices in MIA, the quantitative method and the structure in which the results are offered.

The researchers have gathered a corpus of many expressions used by MIA people in different situations for the sake of this investigation. Moreover, the researcher themselves intuition as a native speaker of Arabic.

\section{Analysis Of MIA Data}

To examine the impact of using the mitigating devices in different situations, this study is prepared to show how these devices are used in Mosuli Iraqi Arabic discourse through the speech of fourteen participants. The material in this study is taken from the natives of Mosul composed by various contemporary linguists in English and Arabic within the field of linguistics. The research papers are chosen from recent issues with top impact refereed international journals. The research papers that are selected to be a source for the analysis of this study are authentic and some of them are carefully selected from the website. This researcher selected fourteen participants from different social classes. The data are collected according to the following situations:

1. Apologizing

a) Pana PaStithir wa Allah wa a:sif

I apologise and Allah and sorry

"I apologize by Allah and sorry."

As we can see from the above statement, the mitigating devices a:sif",

'?aAtithir 'sorry for being late' in this situation is being used to show apology

b) Pana a:sif yamৎawad

I sorry man

"I am sorry man".

2. Regret

a) Pana hi:l xajla:na min-ki

I'm very shy with-you

"I'm very shy with you".

In order to mitigate cruelty, people might choose other devices.

b) aStiðir wa Allah illy sa:y yssban Sany

apologize $1^{\text {st }}$ sing. and Allah what happened forced me

"I'm sorry by Allah what happened was against my will"

In this situation people used the words "aStiðir", "xajla:na" to show regret with politeness.

3. To reduce the force of speech 
a) taSaӨarto bi ldaraj wa waqaS almobail wa Pankasayat al fa a tripped $1^{\text {st }}$ sing. in stairs and fall the mobile and broke the screen "I tripped on the stairs and the mobile fell breaking the screen".

b) bidon qasid inta $\underline{f}$ il maiy Gala il kitab Without intention, spilt the water on the book "Unintended, the water is spilt on the book".

In fact, People give explanations and justifications in this situation to be more polite.

4. Reparation:

a) as ${ }^{\complement}$ alih a fafa infa Allah Allah's will, I will repair the screen.

b) yah anafif il kita:b I will dry the book.

To reinforce the apology, we observe that Mosuli people use this strategy in this situation.

5. Description of damage:

a) il $\mathrm{a} a \mathrm{fa}$ Pankasayat the screen broken "The screen is broken".

b) ilkitab imnaqa؟ the book wet "The book is wet".

With respect to their semantics, in this situation people describe the nature of the damage or the wrong deed.

6. The promise for not repeating the offence

a) aw hidak ha:y awal wa a:xir mara promise $1^{\text {st }}$ sing. this first and last time "I promise that this is the first and the last time".

b) Ma tinfad infa Allah

Not returned Allah willing

"It will not be repeated by Allah willing".

Women used this strategy more than men because they consider it as a prestige.

7. Greeting

a) ilgowa yaba

Power you

"Power given to you"

b) Allah ysądak Samo

Allah help you cousin

"May Allah help you "

Iraqis use these expressions to show the familiar and real relationships with each other. In this situation, they use such devices as politeness markers.

8. Death

a) Allah ysaburkum 
Allah patience you

'May Allah bless you with patience'

b) a:khir il ahzan infa Allah

last the sadness will Allah

'The last sadness, Allah's will'

In sorrowful situations, people express their feelings by using some of these words and expressions in order to console the person for his loss. People use the mitigating device as in "I'm sorry to hear that" in order to be more polite and lesson the force of these hard situations.

9. Congratulations:

a) Sala il xiir wa il baraki on the good and the blessing

'Congratulations'

b) taha:nina wa alif mabruk congratulations and thousand blessings

"Our Congratulations"

The Iraqi people use these expressions to show their joy and pleasure on happy occasions.

10. Travel

These expressions were used to show politeness and express interest and wishing a nice time during travel.

a) Tiqayad Salaa nafsak

Care $2^{\text {nd }}$ sing. on yourself

'be careful'

b) safra safi:da

journey happy

"Have a nice journey"

On the basis of the above observations, it is clear that the Mosuli Iraqis attempt to elaborate the most frequent expressions that are considered to be mitigated. i.e. mitigating devices.

\section{RESULTS AND DISCUSSION \\ Indirect Speech Acts}

Holmes (1984: 351) points out that being indirect helps speakers to mitigate the force of their speech acts. As Fraser (1980: 345) notes, an indirect way of requesting would be I would appreciate it if I were left alone.

to indicate that the speaker is demanding that he is left alone and the receiver is obliged to do so.

\section{Impersonal Constructions}

Fraser (1980:349) postulates a set of distancing techniques which consist of mitigating a request. 
Journal of Arabic Learning

DOI: $10.18860 / \mathrm{ijazarabi.v4i3.9861}$

ISSN(print): $2620-5912$ | ISSN(onIine): $2620-5947$

ejournal.uin-malang.ac.id/index.php/ijazarabi/index

1. For example, the owner of a flat may ask his tenant to use his property for a specified amount of time. The tenant is obliged to accede to the agreement and agree to use the property for the time stated by the owner.

\section{Disclaimers}

Fraser (1980: 349) clarifies that disclaimers help a speaker to preface his/her main thought with the possibility that he/she may be incorrect in what follows. Therefore, disclaimers ensure that the request which is often declarative in nature is mitigated otherwise it will produce an unwelcome effect: It is time to come in. (Request)

\section{Parenthetical Verbs}

Those verbs such as guess, expect, conclude, etc. produce a mitigating effect (Fraser: 348)

This is the way, I guess.

The tag phrase 'I guess' is mitigating as it allows the listener to disagree with the statement.

\section{Tag questions}

This device is expressed as in: I am right, aren't I?

This sentence asserts that I am right but without giving the idea of finality, and therefore, presenting the supposition of being open to debate.

\section{Hedges}

A specific type of mitigation is called 'hedge. It is a device that is used to lesson the impact of a speech. As Fraser (1980) states, "some the expression which Lakoff (1972) called 'hedges' can be used to mitigate".

Hedges leave a speech open for the recipient to enact his/her own utterance and are determined by the absence of exact propositional. For example, might, about, perhaps, possibly, etc. They are commissives which are used when the speaker is speaking about his plans:

1. I must study hard for the next exam

2. I shall take you with me for the party

3. I would like to invite you to come dinner.

4. Have more rice, if you can.

The Arabic equivalents of mitigation which constitute a distinct and wellestablished grammatical category will be described in detail later in the paper. Two subcategories of modality conveyed by such modal auxiliaries are examined, namely, epistemic and deontic modality like gad and rubbamaa.

\section{Euphemism}

The avoidance of uttering taboo words is linked to euphemism which is specific to the cultural context it is being applied on. Euphemism is the substitution 
by a pleasant or less violent expression in place of one that may upset or advise something unkind to the hearer. It is commonly used in all societies to avoid being offensive or impolite. Therefore, to maintain better social relationships and for the exchange of ideas, interlocutors tend to use euphemized words (Ali and Salih, 2020: 37). This is directly related to mitigating devices in communication. In some cases, they may be used derogatively and hence convert to dysphemism as in:

'Concentration camp' which is a term for describing camps.

Euphemism can be deifined as "a figure of speech in which a delicate word or expression is substituted for one which is offensive to good manners or to delicate ears" The new Webster English Dictionary (vol. 1: 30).

The term 'euphemism' originates from the Greek euphèmism(os), which means the use of good words. Lyons (1981:151) refers to this term as "the avoidance of taboo words". For Leech (1974:53) as "more lovely or [more] acceptable than it really is".

\section{Categorization Of Mitigating Devices}

For example: "could you help me?" and "would you mind cleaning the window a little bit"?

The above examples are the head acts in the two requests because they are the elementary units that can be used independently to carry out the requesting acts.

\section{Internal mitigating devices}

The effect of speech acts of inviting can also be mitigated. Internal Mitigating Devices are of two types (a) syntactic down-graders and (b) (lexical down-graders). The former is found widely in English whereas the latter is concentrated in Arabic.

\section{Syntactic downgraders}

in this type, the speaker employs to mitigate the annoyance strength of the request head act. They are:

Questions:

Can/Will you give me the book please?

\section{Wish "anticipation speech":}

In order to perform the request by the listener, the devices such as 'wish' or 'hope' are used:

Balki: tuqradni kam filis iða Sandak

hope lend $2^{\text {nd }}$ sing. some money if have $2^{\text {nd }} \operatorname{sing}$.

"I hope that you can lend me some money if you have."

\section{Lexical/phrasal down graders}

This ypes includes an expression that uttered by a speaker towards the hearer to lessen the illocutionary force of the requesting act at the lexical/phrasal level. 


\section{IJAZ ARAB I}

Journal of Arabic Learning

DOI: $10.18860 / \mathrm{ijazarabi.v4i3.9861}$

ISSN(print): 2620-5912 | ISSN(onIine): 2620-5947

ejournal.uin-malang.ac.id/index.php/ijazarabi/index

\section{Politeness markers}

Politeness markers are devices added to an utterance to express deference or a request for cooperation. In general, the word 'please' and the phrase 'if you wouldn't mind' are commonly used in English to show politeness. The same rules apply in Arabic for example radza:?an or minfadlak. Consider the following utterances:

Can you please clean the room today?

$\operatorname{minfad}^{\mathrm{S}}$ lak, hal tunad ${ }^{\mathrm{S}}$ if alyurafta al yaum?

\section{Consultative devices elements}

Here, the speaker tries to ask for the listener's cooperation through phrases like would you mind? Or could you please? The following examples illustrate this further:

1. Would you mind pushing the car for me?

2. All right and if it is all right?

3. Is it possible to walk in here?

\section{Downtoners Elements}

These are elements which moderate the impact of the speaker's utterance. For example: " simply, possibly, perhaps, just, rather, and maybe) as in:

Could you simply call him now?

\section{Understates adverbial modifiers}

Could you please help me a little bit? ( a bit, a second, a minute)

In the English language, adverbs are effective linguistic tools or strategies which are crucial in the process of generating meaning in discourse (Hazem and Kanaan, 2020:2)

In this part, the results of data analysis relating to each research question that are given by authors in this study. The frequency and the kinds of mitigating devices used by informants are measured. The participants of this study included fourteen (seven females and seven males) native speakers of Mosuli dialect to show some mitigating devices in different situations and analyse these data according to Fraser 1981 model.

The following table (Table 1) Shows the most popular devices that are used in different situations:

Table 1: The most popular mitigating devices in MIA

\begin{tabular}{|c|c|c|c|}
\hline Participants & $\begin{array}{c}\text { Mitigating devices in } \\
\text { MIA }\end{array}$ & glossing & meaning \\
\hline A & يصير خير ان شاء & ys'ir xiir infa Allah & $\begin{array}{c}\text { ill be fine if Allah } \\
\text { will }\end{array}$ \\
\hline B & سهلي سهلي & sahli sahli & easy easy \\
\hline C & بسيطة بسيطة & 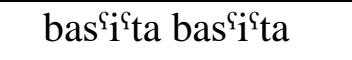 & Simple simple \\
\hline D & الله كريم & Allah kari:m & h $h$ is the generous \\
\hline
\end{tabular}


Journal of Arabic Learning

DOI: $10.18860 / \mathrm{ijazarabi.v4i3.9861}$

ISSN(print): 2620-5912 | ISSN(online): 2620-5947

ejournal.uin-malang.ac.id/index.php/ijazarabi/index

\begin{tabular}{|c|c|c|c|}
\hline $\mathbf{E}$ & توكل بالله يمعود & akal ba Allah yam & Ian trust Allah \\
\hline $\mathbf{F}$ & هانت هانت ان شاء & hanat hanat & $\mathrm{s}$ a bout the end \\
\hline G & ماشي ماشي تدلل & ma $\int i$ ma $j i$ tadalal & $\mathrm{OK} \mathrm{OK}$ \\
\hline H & انت كريم ونحن & $\begin{array}{c}\text { Pnta karim wo niћna } \\
\text { nistahil }\end{array}$ & $\begin{array}{c}\text { You are generous } \\
\text { and we deserve }\end{array}$ \\
\hline I & يواش يواش & yawa yawa & Step by step \\
\hline $\mathbf{J}$ & سيم بالك & sim balak & Be careful \\
\hline
\end{tabular}

It is worth mentioning here that the researchers have arrived at the conclusion that there are some mitigating devices which are more commonly used in MIA.

Through the above table it is found that $A$ is the most common expression. It is used in more than one situation; for example, if someone has a request and the other one has to think about it. So, he will say ys ${ }^{\text {Sir }}$ xiir in fa Allah ' It will be fine if Allah will'.

In addition. $B$ is infa Allah ' if Allah will' is also common in everyday conversation. It is used for example in the case of examination or an interview.

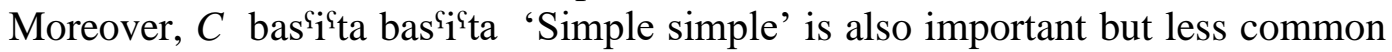
than A \& B. Whereas $D$ Allah kari:m 'Allah is the generous' has been found that it is used by a number of people to mitigate different situations. People also used $E$ twakal ba Allah yamSawad 'Man trust Allah' in certain situations for instance in telephone calls. Moreover, $F$ hanat hanat 'It is about the end' is also used by a majority of Mosuli and non Mosuli people but less frequently than $A$ and $B$. It is also used when parents wish to give advice to their kids in difficult times.

Other people are interested in using $G$ ma $1 \mathrm{i} \mathrm{mafi} \mathrm{tadalal} \mathrm{'ok} \mathrm{ok'} \mathrm{to} \mathrm{make} \mathrm{a} \mathrm{pledge}$ or promise to mitigate the situation. What's more, $H$ ?nta karim wo niћna nistahil 'You are generous, is also a polite expression.

Finally, the last two mitigating devices that are used in MIA, $I$ yawa yawa 'Step by step' $J$ sim balak 'Be careful' are devices that are found to be less frequently used by the Mosuli people. However, they are found in the speech of old people.

( yawaf yawa 'Step by step' sim balak 'Be careful'. For more clarification, the following figure shows that change. 


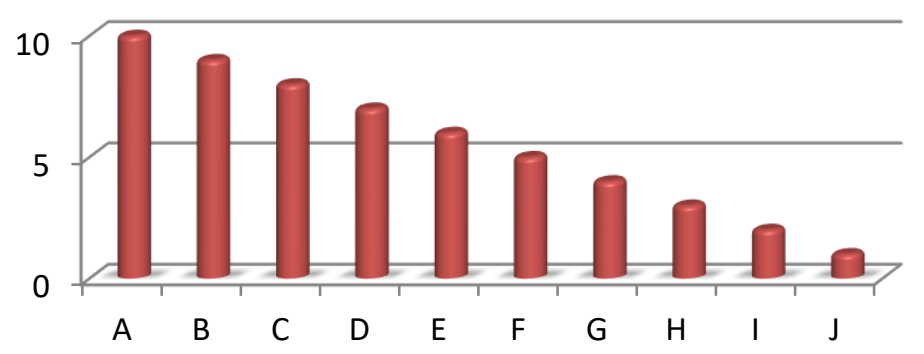

Figure 1: The frequency of mitigating devices in Mosuli Iraqi Arabic

1. Pl-bet bet-kum

the- house house-yours

'The house is yours'

The expression is used when some people come to visit others suddenly. They also said yam Saud naћna ahil 'Man, we are one family'

2. Ptsahal maSana belsi@r Jwiya

Indulge with us with price little

' help us in price'

This above expression is used in the market conversation when the speaker needs to buy and sell.

3. mans ${ }^{\complement}$ wriin ba-ৎawn Allah

Victories with -help Allah

'We will win by the help of Allah'

The expression (57) is used by speakers in motivated situations.

Furthermore, the following popular expressions are used to mitigate the situations of a request.

4. s $^{\complement}$ ar tidalal

ok flirtation

'It is done, ok'

5. tu?mur

Pamr

Order- $2^{\text {nd }}$ sing. order

' your order is order'

6. iGtabirha kimlat considered done

7. had'ir ba Giyun-i

Ok in eyes- my

' with my pleasure'

The expressions (58-61) are used to mitigate the situation of request. Moreover, they are considered as a promise to achieve the order.

On the other hand, the clinic situation and the conversation between the physician and the patient also has some expressions.

8. Pzma w taSdi infa Allah

crise and pass if will Allah 
'this will pass if Allah will'

9. maja Allah baYdak Jabab masha Allah still young

'Masha Allah you are still young'

10. Samalitk-i xafifi la tifili ham

Operation-your easy not carry worry

'your operation surgery is easy, don't worry'

11. xuð d-dawa? wa tithasan bi aqrab waqt

take the-drug and improve in early time

'take the drug and you will be better soon'

Thus, the expressions in (62-65)are used to mitigate the situation and psychologically, make the sick people feel better. In addition, the common expression that are used in the exam are:

12. ?nta Sat'ir ma ynxaf Saliik

you clever not fear on you

'without hesitation, you are clever'

13. qool ya Allah w fut Gal l-imthan bi-kul Oiqah

say Allah and enter to the-exam with-all confidence

'say Allah and enter the exam with full confidence'

It is clear from (52) that the exam situation has some expressions as shown above. Finally, the following figure illustrates mitigating devices in accordance with their occurrence in day-to-day communication by MIA.

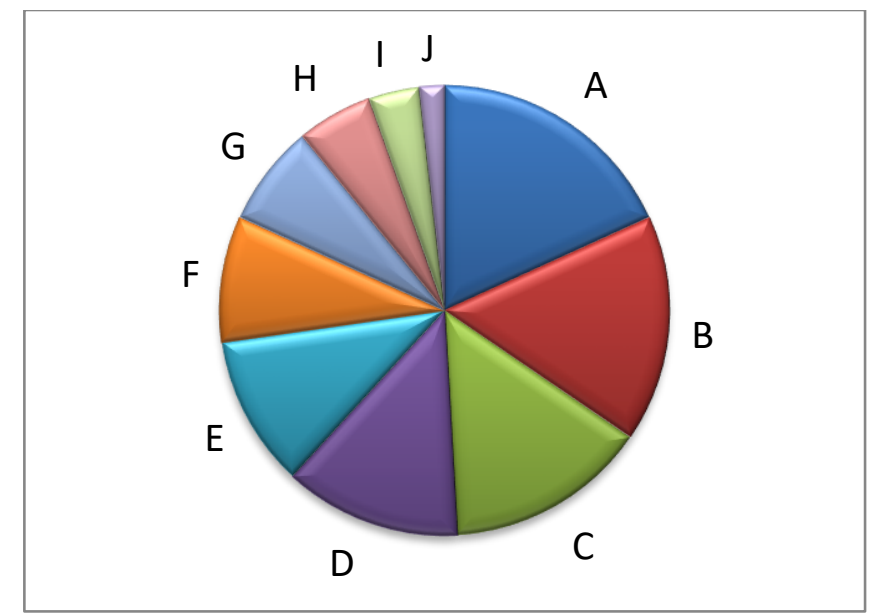

Figure 2: The occurrences of Mitigating devices in MIA

\section{RESULTS AND DISCUSSION}

"Modern Standard Arabic and Iraqi Arabic varieties share certain grammatical features" ( Hazem 2017:365). In order to change your life for the better, the following mitigating devices are commonly used:

10 daily rules to transform your life for the better: 
IJAZ ARABI

Journal of Arabic Learning

DOI: $10.18860 / \mathrm{ijazarabi.v4i3.9861}$

ISSN(print): $2620-5912$ | ISSN(onIine): $2620-5947$

ejournal.uin-malang.ac.id/index.php/ijazarabi/index/530

\section{Marhabaa $=$ Welcome:}

Although it is a simple word in many languages, it gives the impression that you are a positive person.

radza:Pan or minfadlak = Please:

It is one of the magic words that must be used on a daily basis. When you say 'please' the person switches from the imperative form to the request. This in turn shows respect for you and others.

fukran $=$ Thanks:

Whether someone is on their way to do something they didn't have to like leaving a seat for you or doing a chore like finishing a piece of paper you need, saying 'thank you' is a small, gesture to make the other person feel appreciated, grateful, and kind.

Sala r-ruhi wa s-sifa = You're welcome:

After thanking, a polite response is 'You're welcome,' 'My pleasure,' or 'You're welcome,' rather than 'No problem', which sends the wrong message. The first words give a kinder and more positive response in front of others. The idea is not to belittle the other.

\section{Safwan =Sorry:}

This method is useful for returning to social equilibrium, getting the other person's attention, or providing a way out of a situation or a polite transition between sentences. For example when you ask for permission or offer an apology by saying 'excuse me'.

\section{taðakar ism faxs ${ }^{\complement}$ l-?axar Remember the name of the other person:}

When talking to customer service or individuals representing a service, some people are unaware of calling people by their name. So, it's best to know the person's name and say their name politely during the conversation, as this will make them feel appreciated, important and positive.

?anaa saSiid liru?yatik = I'm happy to see you:

From the rules of conversation between two parties, when you ask the other party about your condition, it is better to answer that you are happy to see him. This gives the impression that their presence causes you joy.

haaðaa lut'fun mink = That's kind of you:

Accepting a compliment can be an appreciation for people, while neglecting it can indicate that you don't appreciate what is given to you. So, learn to say phrases like: "That's so kind of you." These expressions show gratitude, humility, and put a smile on everyone's face.

\section{Taqdiim l-ta?aazy $=$ Offer condolences:}

Here, it is possible to say something as simple as, "I'm so sorry for your loss." It can be said, written, or sent as a telegram of condolence. Offering such words makes the other person feel that you care.

laqad laahað' ${ }^{\mathrm{it}}{ }^{\mathrm{s}} \mathrm{kam}$ anta dzayd fii $=$ noticed how $\operatorname{good}$ you are at...: 
Journal of Arabic Learning

DOI: $10.18860 / \mathrm{ijazarabi.v4i3.9861}$

ISSN(print): $2620-5912$ | ISSN(onIine): $2620-5947$

ejournal.uin-malang.ac.id/index.php/ijazarabi/index/

It is an expression to point out the other's strength and ask them to talk about it. Concentrating on what this person is good at puts you in a positive light and makes that person appreciate you.

To sum up, in the literature on mitigation, there has been an attempt to equate mitigation with politeness. It can be argued that mitigation is the internal modifications in speech whose purpose is to modulate or reduce the effect of the speech act whereas politeness is an overall strategy. Mitigation devices adopted by speakers to mitigate their speech. Regarding euphemism, it has been found to constitute a main type of mitigation, which is supported in Ali and Salih's (2020) study. Hedges and euphemism are the the basis two types of mitigation devices as they consist of the most effective ways to mitigate speech. The current study has tried to answer all the research questions. In the present study, the features that are considered typical and distinctive of MIA mitigating devices used in MIA have been outlined. The data has revealed the relevant features, both those which were present and those which were conspicuous by their absence. The absent features were rationalized and commented upon.

The first research question was: Are mitigating devices present in Mosuli Iraqi Arabic? Most of the features listed in the discussion of the present study, can easily be observed in the speech acts. Regarding the research question: What are the most popular mitigating devices that are used in Mosuli Iraqi Arabic? The findings are discussed in the analysis and the results and their percentages were presented in detail. The findings showed that the most popular mitigating devices are applied according to the situation. The next research question was: Is the context clear for the speaker and the listener? The answer to this question is: yes. The context plays a pivotal part in the production of speech. Finally, the statistical data of all the prominent features have been provided to answer the question: Will using the mitigation devices lesson the force of direct speech? The answer to this question is: yes. Mitigation devices represents the syntactic, semantic, morphological and discoursal devices adopted by speakers to mitigate their speech. It has been found that semantic change is the most operative category of Euphemism one as it considers devices such as widening, litotes, understatement, indirection, and abstraction that can result in less direct or understated meanings. The previous sections illustrate all the research questions sequentially.

Finally, mitigating devises which were proposed by Fraser's (1990) can be seen in the following tree diagram: 
Mitigating Devices

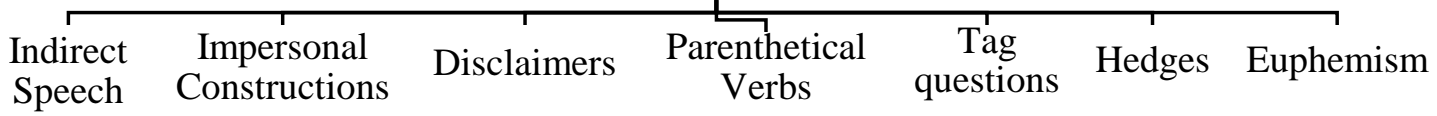

Acts

\section{CONCLUSIONS}

It is already made clear in the introduction that the study is not a comparative analysis in the true sense. The purpose to analyse the English examples was just to show the validity of the framework for languages from different families. This paper has examined the use of mitigating expressions used by MIA speakers in their social context. The investigation has revealed contrastively how mitigating devices are performed in MIA and English and in the linguistic representation from different situations, shedding light on the levels of directness found in selected situations in both languages.

The most important findings in this study are that mitigating devices are utterances by the speakers of MIA used to express appropriate politeness in their speech in various situations. These expressions have different structures and can be intensifiers, politeness markers, etc. The well-defined category of English modal auxiliaries is used here as a frame of reference, and Arabic equivalents are presented as translations of these modal auxiliaries. It is of course easiest to say that modality in Arabic is a lexical category. However, even this initial investigation indicates that the various exponents of modality in Arabic can be captured by a grammatical rule. The findings of this investigation have strong implications for those teaching the pragmatic elements of these languages to learners of both Arabic and English as foreign languages.

The effect that (in) directness has upon each culture and the imposition of cultural stereotypes should not be underestimated. Finally, the researchers give a description of mitigating devices within a context-update model of discourse in Arabic, viz MIA and it separates discourse situations conducive to the suitable use of these devices. This paper has provided a thorough account of the linguistic representation of mitigating devices from the native speakers of MIA and the authentic books in English. The substantial empirical support for the findings examples sheds enough light to reach significant conclusions concerning the representation of these expressions and contributes to the pragmatic corpus of local grammar descriptions in the teaching and learning of speech acts. Following this line of investigation, other types of speech acts could be further researched in order to develop a broader view of the linguistic representation of speech acts in audiovisual texts. For further studies, the researchers suggest that the role of intonation 


\section{IJAZ ARABI}

Journal of Arabic Learning

DOI: $10.18860 / \mathrm{ijazarabi.v4i3.9861}$

ISSN(print): 2620-5912 | ISSN(onIine): 2620-5947

ejournal.uin-malang.ac.id/index.php/ijazarabi/index

in MIA is an interesting topic lending itself to mitigation and furthering interpersonal relationships.

\section{ACKNOWLEDGEMENTS}

We, the researchers of this paper wish to thank and express our deep gratitude to Mrs. Ozma Siddiqui (King Abdulaziz University, Jeddah, Kingdom of Saudi Arabia) for reviewing and for her useful comments on an earlier draft of the paper.

\section{REFERENCES}

Abdul Sattar, H., Lah, S. and Suleiman, R. (2009). Iraqi postgraduates' production and perception of requests: A pilot study. The International Journal of Language, Society and Culture, $56-70$.

Al-Ali, M. and Alawneh, R. (2010). Linguistic mitigating devices in American and Jordanian students' requests. Intercultural Pragmatics, 7(2), 311-339.

Al-Ali, M. and Sahawneh, M. (2008). An investigation into the generic features of English requestive e-mail messages. Professional Communication, 2(16), 40- 64.

Ali, A. I. and Salih, S. M. (2020) "A Taxonomy of Mitigation Devices in English Language”, Koya University Journal of Humanities and Social Sciences, 3(1), pp. 31-40. doi: 10.14500/kujhss.v3n1y2020.pp31-40.

Allan, K., Burridge, K.(1991). Euphemism and Dysphemism: Language Used as a Shield and Weapon. Oxford University Press, New York.

Brown, G. \& Yule, G. (1983). Teaching the Spoken Language: An Approach Based on the Analysis of Conversational English. CUP

Brown, P. \& Levinson, S. (1987). Politeness: Some universals in language usage. Cambridge: Cambridge University Press.

de Pablos-Ortega, C. (2020). Directive Speech Acts in English and Spanish Filmspeak. Pragmática Sociocultural / Sociocultural Pragmatics, 8(1), 105-125. https://doi.org/10.1515/soprag-2020-0001

Fraser, B. (1980). Conversational Mitigation. Journal of Pragmatics, 4, 341-350.

Fraser, B. (1981). Perspective on Politeness. Journal of pragmatics. 14,219-236.

Fraser, B. (1990). Perspectives on politeness. Journal of Pragmatics, 14, 219-36.

Caffi, C (2007), Mitigation, Elsevier, Amsterdam.

Gove, P. B. (Ed.). (1986). Webster's Third New International Dictionary. Cambridge, Massachusetts: Riverside Press.

Hazem, A. H. (2017 b). Subject Verb Agreement in Iraqi Arabic and Modern Standard Arabic: A Comparative Study. Journal of Al-Frahedis Arts 2(28):363-74. http://dx.doi.org/10.25130/art.v2i28.284.

Hazem, A. H., and Meteab, W. Y. (2019). Nominal Constructions in Modern Standard Arabic With Reference to English. International Journal of Applied Linguistics and English Literature 8(2):97-101. http://dx.doi.org/10.7575/aiac.ijalel.v.8n.2p.97 
Hazem, A. H. and Kanaan, M. H. (2020). Domain Adverbs in Legal English Texts: Problems and Strategies. IUP Journal of English Studies. Vol. XV, No. 4. India.

Holmes, J. (1995). Women, Men and Politeness. New York: Longman.

Khuder, S. A., Hazem, A. H. \& Kanaan, M.H. (2021). The Role of Discourse Markers in Organizing Literary Discourse: H.G. Wells' The Time Machine as a Case Study. ADAB AL-RAFIDAYN 84 (51), 1-26

Lakoff, G. (1972). Hedges: a study in meaning criteria and the logic of fuzzy concepts. Chicago Linguistic Society, 8, 183-228. Leech, G (1974) Semantics. London: Penguin Books Ltd.

Lyons, J. (1981). Language, meaning, and context. London: Fontana. Wafi, A.A. (1983). Language and Society. Okaz Bookstores Companies. Riyadh.

Wardhaugh, R.(2006). An Introduction to Sociolinguistics. Blackwell Publishing, Malden, MA.

Watts et al, Richard. (1992). Linguistic politeness and politic verbal behavior: reconsidering claims for university. 